Original Research Paper

\title{
Effect of Probiotic Feed Additives on Honeybee Colonies Overwintering
}

\author{
${ }^{1}$ Galina Mishukovskaya, ${ }^{2}$ Marat Giniyatullin, ${ }^{2}$ Varis Tuktarov, \\ ${ }^{3}$ Airat Khabirov, ${ }^{1}$ Fail Khaziahmetov and ${ }^{1}$ Aygul Naurazbaeva \\ ${ }^{I}$ Department of Animal Physiology, Biochemistry and Feeding, Federal State Budgetary Educational Establishment of Higher \\ Education "Bashkir State Agrarian University", Ufa, Russian Federation \\ ${ }^{2}$ Department of Beekeeping, Private Animal Husbandry and Animal Breeding, Federal State Budgetary Educational \\ Establishment of Higher Education "Bashkir State Agrarian University", Ufa, Russian Federation \\ ${ }^{3}$ Department of Physiology, Biochemistry and Feeding Animals Department, Federal State Budgetary Educational \\ Establishment of Higher Education "Bashkir State Agrarian University”, Ufa, Russian Federation
}

\author{
Article history \\ Received: 30-07-2020 \\ Revised: 14-11-2020 \\ Accepted: 17-11-2020 \\ Corresponding Author: \\ Galina Mishukovskaya \\ Department of Animal \\ Physiology, Biochemistry and \\ Feeding, Federal State \\ Budgetary Educational \\ Establishment of Higher \\ Education "Bashkir State \\ Agrarian University", Ufa, \\ Russian Federation \\ Email: mishukovskayaya@rambler.ru
}

\begin{abstract}
The paper presents the study on the effect of two types of probiotic feed additives of different composition on the quality of honeybee colonies during wintering. Feed additive called SpasiPchel contains 2 strains of bacteria Bacillus subtilis anfeed additive PcheloNormosil contains Lactobacillus and Bifidobacterium strains and arabinogalactan (prebiotic isolated from Siberian larch needles). If honeybees received Spasipchel and Pchelonormosil during the feeding in cages their lifespan increased. Honeybee colonies that received Spasipchel in autumn exceeded the control group by $21.3 \%$ in colony strength and by $58.7 \%$ in the number of sealed brood in spring. Food consumption in these colonies per honeybee frame during the winter period was $22 \%$ lower. Honeybee colonies, that received PcheloNormosil feed additive, were slightly behind in strength compared to the control colony during spring, but surpassed it by $23.5 \%$ in the number of sealed brood. Further research should be made to identify optimal composition of probiotics that are better at preserving honeybee colonies under the conditions of the continental climate characterized by long cold winters.
\end{abstract}

Keywords: Honeybees, Honeybee Colonies Overwintering, Probiotics, Honeybee Colony Strength, Sealed Brood, Feed Consumption

\section{Introduction}

Probiotics have become widely used in various branches of animal husbandry. They are applied to prevent and treat intestinal infections, to restore the microflora of the digestive tract after antibiotics or antibacterial chemotherapeutic agents. Probiotics improve digestive processes and stimulate non-specific immunity (Andreeva et al., 2018; Khaziakhmetov et al., 2018a; 2018b; Chernitskiy et al., 2019). Data on the effectiveness of probiotics in beekeeping are contradictory. First of all, this concerns the effect of probiotics on the immunity of honeybees. Thus, nine strains of bacteria belonging to Enterococcus sp., Weissella sp. and Lactobacillus sp. are able to inhibit the growth of Paenibacillus larvae in vitro causative agent of American foulbrood (Yoshiyama et al., 2013). According to a group of Canadian researchers, honeybee larvae resistance to $P$. larvae infection increased under probiotics (Daisley et al., 2017; 2020). Probiotics stimulate the expression of Def-lgene. This gene is a peptide that plays a key role in protecting honeybee larvae against this infection. According to (Stephan et al., 2019), when colonies received probiotics, there was no an increase in their resistance to American foulbrood. Although, the researchers mentioned above do not deny the antagonistic effect of lactic bacteria on P. larvae in a larval stage of honeybee organism.

The issue of the effect of probiotics on economic characters of honeybee colonies is not unanimous. Some authors note an increase in honeybee productivity when honeybee colonies recieve sugar syrup enriched with Lactobacillus salivarius and B. subtilis (Sabaté et al., 2012; Fanciotti et al., 2018). Moreover, the beneficial bacteria reduced the incidence of two important bee diseases: Nosemosis and varroosis (Audisio, 2017). 
Probiotics proved to have effect on egg production of the queen and an increase in the honeybee colonies strength (Audisio, 2017; Bleau et al., 2019). At the same time, according to (Horton et al., 2015) there was no direct correlation between colony productivity and the composition of honeybee gut microflora. The state of the gut microflora definitely affects the health of honeybees and the honeybee colony well-being (Kešnerová et al., 2017; Bonilla-Rosso and Engel, 2018; Raymann and Moran, 2018). The composition of microflora is influenced by various factors such as: Food sources (honey plants), plant phytoncids, pesticides and medications used in beekeeping (Raymann and Moran, 2018). All these factors can have a beneficial effect on some types of bacteria and inhibit the development of others, introducing a certain imbalance in the intestinal microbiota.

The composition of the honeybee intestinal microflora may vary by season (Ludvigsen et al., 2015; Maes et al., 2016; Kešnerová et al., 2020). Feed shortage and temperature stress can lead to a decrease in the immunity of honeybees. In addition, the physiological characteristics of honeybees, such as impossible defecation in winter, form a risk factor for developing infectious diseases. Both, the health of a bee colony and its economically useful signs, associated with bee colony productivity, depend on the composition of microflora of adult and established generation of winter adults honeybees. While the losses of honeybee colonies during wintering is the main problem of beekeeping in countries with long winters, there is very little information in scientific literature about the effect of probiotics on the quality of honeybee overwintering. The purpose of our research was to study the effect of probiotic feed additives as part of autumn feedings on the status of honeybee colonies, i.e., their survival, strength, feed consumption, amount of brood, before and after wintering.

\section{Materials and Methods}

Probiotic feed additives developed by the "Research and Innovation Enterprise Bashinkom" Limited Liability Company were used during the experiments. They were SpasiPchel, which contains 2 strains of B. subtilis and PcheloNormosil, containing Lactobacillus and Bifidobacterium strains and arabinogalactan (prebiotic isolated from Siberian larch needles).

\section{Cage Experiments}

To obtain 1-day-old honeybees, combs with brood originating from one queen bee were transferred, on the 20th day of bee development, to an air-conditioned chamber and kept at a constant temperature of $35^{\circ} \mathrm{C}$ and at a humidity of $60 \%$. After emerging, honeybees were kept under laboratory conditions, in complete darkness $\left(25^{\circ} \mathrm{C} ; \mathrm{H}=65 \%\right)$ in wooden cages, occupied by 55 specimens. The cages were divided into groups. There were 3 cages in each group. All groups received 50\% Sugar Syrup (SS). The control group received pure sugar syrup and the experimental groups received it with feed additives: Experimental groups 1, 2 and 3 received SpasiPchel probiotic in doses of 1.2 and $3 \mathrm{~mL}$ per 0.51 of sugar syrup. Groups 4, 5 and 6 received the same doses of PcheloNormosil. Food and water were added as they were consumed by honeybees. Every 2 days, the number of dead adult bees was recorded in each cage to evaluate mortality rate in each group. The experiment lasted for 25 days.

\section{Field Tests}

Research was conducted at the apiary of Bashkir State Agrarian University, which is located in the Northern forest-steppe natural and climatic zone of the Republic of Bashkortostan, $28 \mathrm{~km}$ from Ufa city (Russian Federation).

To assess the effect of probiotics on the quality of overwintering, 3 groups of 24 honeybee colonies were formed. Feeding of honeybee colonies was carried out at the end of August 2018. Honeybee colonies of the control group received pure sugar syrup. Honeybee colonies of the experimental groups were fed syrup with feed additives: The experimental group 1 received Spasipchel in a concentration of $2 \mathrm{~mL}$ per 0.51 of syrup, the experimental group 2 - Pchelonormosil in the same concentration. Feeding was carried out in three stages with 3 day intervals. 0.5 liters of feeding per bee colony was poured in the evening into side feeders.

In November, when constant cold weather conditions occured $\left(-5^{\circ} \mathrm{C}\right)$, hives with honeybees were brought into a semi-underground indoor-wintering building. During the entire wintering period the temperature in it was kept within $0 \pm 5^{\circ} \mathrm{C}$ with relative humidity of $70-85 \%$, measured with a hygrometer-psychrometer VIT-1. The hives were taken out from a wintering building in early April 2019.

Status of honeybee colonies was assessed twice - in November 2018 before they were placed in indoorwintering building and in April 2019 after they were taken out of wintering building, the strength of colonies was calculated by the number of frames inside a beehive covered with honeybees on both sides ( 1 frame $=\sim 2,430$ bees). The amount of sealed brood in the nests of bee colonies was estimated using a grid with $5 \times 5 \mathrm{~cm}$ squares that covered the entire side of a comb. Values from the frame measurements were summed to obtain brood estimate for the colony.

Feed consumption was calculated according to the difference in the mass of the hives before they were placed in a indoor-wintering building and after they were taken out of it. 
To determine the degree of the fat body development, 20 worker honeybees were selected from each group. During dissection, the head was separated from a honeybee, then the intestine was removed with tweezers pinching the last segment of the abdomen. Scissors were inserted in the abdomen hole, then two longitudinal incisions were made in the boundary area of sternites and tergites. Sternites were removed and saline was pipetted into the abdominal cavity. At the same time, a white coating of chitinous walls of air bags floated up and was withdrawn, clearing the space for inspection, using a microscope at 24 - fold magnification. The assessment of the degree of the fat body development was performed using the method of (Maurizio, 1954).

To determine the-level of infestation with Nosema spp. spores 50 flying bees were selected at hive entrance. Samples were stored at $-20^{\circ} \mathrm{C}$. While studying honeybees, their abdomen was separated from them and put into a measuring cylinder. Then, $1 \mathrm{~mL}$ of water per honeybee was added in the cylinder. The contents were carefully crushed in a homogenizer to get suspension. A drop of the suspension was examined in a hemocytometer (Marienfeld - cell counting chamber made of special optical glass, with a double counting grid, cell depth: $0.1 \mathrm{~mm}$, system: Neubauer-improved) with increase in $400^{\mathrm{x}}$. Assessment of the damage grade was carried out according to the scale: 1 point - up to 5 million spores per bee, 2 points - from 5.05 million to 25 million spores per bee, 3 points - from 25.05 to 75 million spores per honeybee and 4 points-more than 75 million spores per honeybee.

Statistical processing of the data was carried out by conventional methods of variation statistics using the Microsoft Excel statistical analysis package. The significance of differences in arithmetic mean was estimated using the Student's t-test, the differences were considered statistically significant at $\mathrm{p}<0.05$.

\section{Results}

The analysis of honeybee mortality in cages showed, that when honeybees received SpasiPchel feed additive in any dose with sugar syrup, their mortality slowed compared to bees from the control group. By the middle of the experiment (on the 13th day) death rate of bees which received SpasiPchel ranged from 20.0 to $25 \%$ compared to honeybees from the control group, where the same parameter was $37 \%$ Fig. 1. The best results were obtained in the experimental group 2, where the probiotic was added in a dose of $2 \mathrm{~mL}$ per 0.51 of syrup. Only $50 \%$ of honeybees of this group died on the 25th day after feeding, which is $27.4 \%$ less than in the control group. When using PcheloNormosil feed additive, there was a clear dependence of honeybee mortality on the dosage. The dose of $2 \mathrm{~mL}$ of probiotic per 0.51 of syrup was the best.
The maximum lifespan was recorded in groups that received probiotics with feeding in a dilution of $2 \mathrm{~mL}$ per $0.5 \mathrm{~L}$ of sugar syrup. The difference between these groups and the control group was significant $(\mathrm{p}<0.05)$.

At the end of August 2018, after honey harvesting from sunflowers and various grasses was over, the strength of honeybee colonies was assessed. Then, groups of honeybee colonies, used for the experiment, were formed. At the beginning of the experiment (before feeding), honeybee colonies had an average strength of 9.3 frames, the amount of feed was $10.3 \mathrm{~kg}$. There were 9.8 honeycomb frames in the nest, including 5.3 honeycomb frames with brood.

Before placing honeybees in indoor-wintering building in the first decade of November, the strength of honeybee colonies was visually determined and the hives were weighed. The record of results showed that the strength of honeybee colonies significantly decreased during 2 months (September and October), which is associated with mortality of summer honeybees. At the same time, in the control group it decreased by $41.9 \%$, in the experimental group 1 - by $25.6 \%$ and in experimental group 2 - by $52.2 \%$.

The level of development of the fat body of honeybees was assessed. This indicator increased by an average of 0.8 points, when bees received SpasiPchel probiotic in November Fig. 2. When honeybees received PcheloNormosil, the level of development of the fat body was 0.5 points higher compared to bees from the control group.

According to the obtained results, all honeybee colonies of experimental and control groups had a successful overwintering. In the group of colonies that received SpasiPchel additive in autumn, the indicator of colony strength before wintering was the best and succeeded the same indicator of the control group by $24.1 \%$ Table 1.

Despite the fact, that during wintering, the percentage of weakened colonies in experiental group 1 was slightly higher (by $1.7 \%$ ), even after taking colonies out of the wintering building, they exceeded the control group by $21.3 \%$ in colony strength. The amount of sealed brood in this group significantly exceeded the control value by 1.6 times. Honeybee colonies of the second experimental group, which received PcheloNormosil as additive in autumn, were slightly inferior to the control group in strength in spring, but superior in the amount of sealed brood by 1.2 times. This group also showed the least number of weakened colonies during the wintering period.

One of the important indicators of wintering quality is the consumption of carbohydrate feed. Food consumption per bee colony in experimental groups did not differ from the control group Fig. 3. 


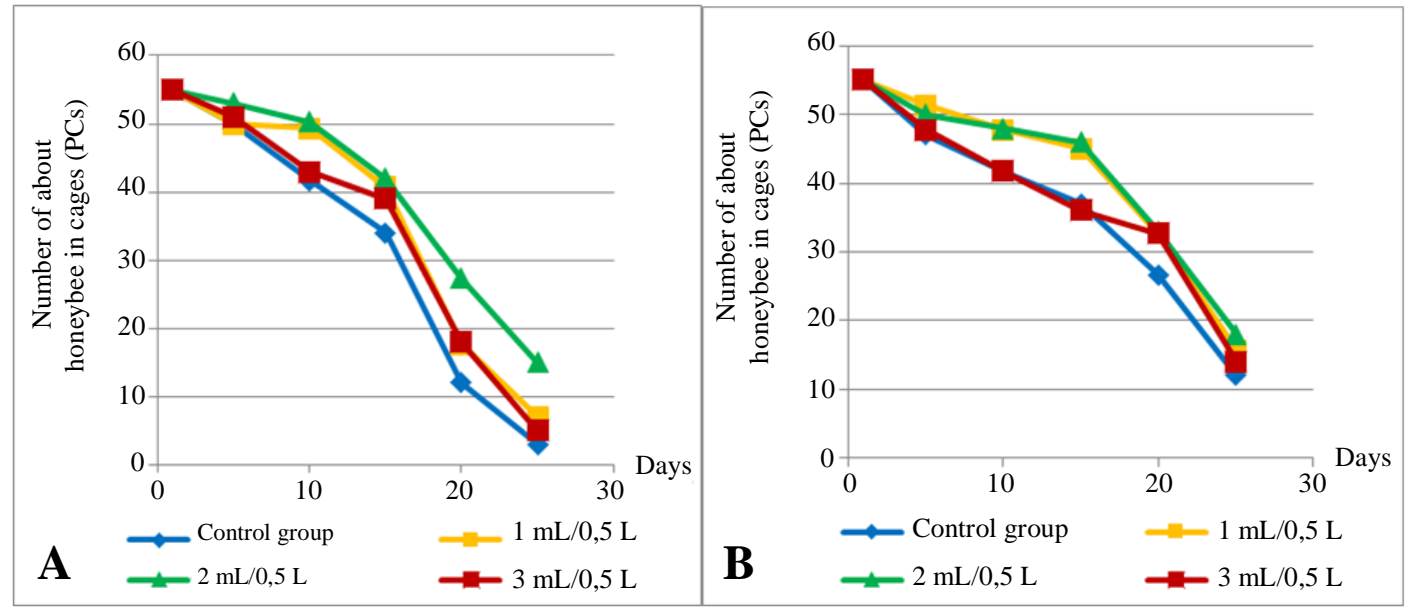

Fig. 1: Dynamics of honeybee mortality in experimental cages: (A) - SpasiPchel, (B) - PcheloNormosil

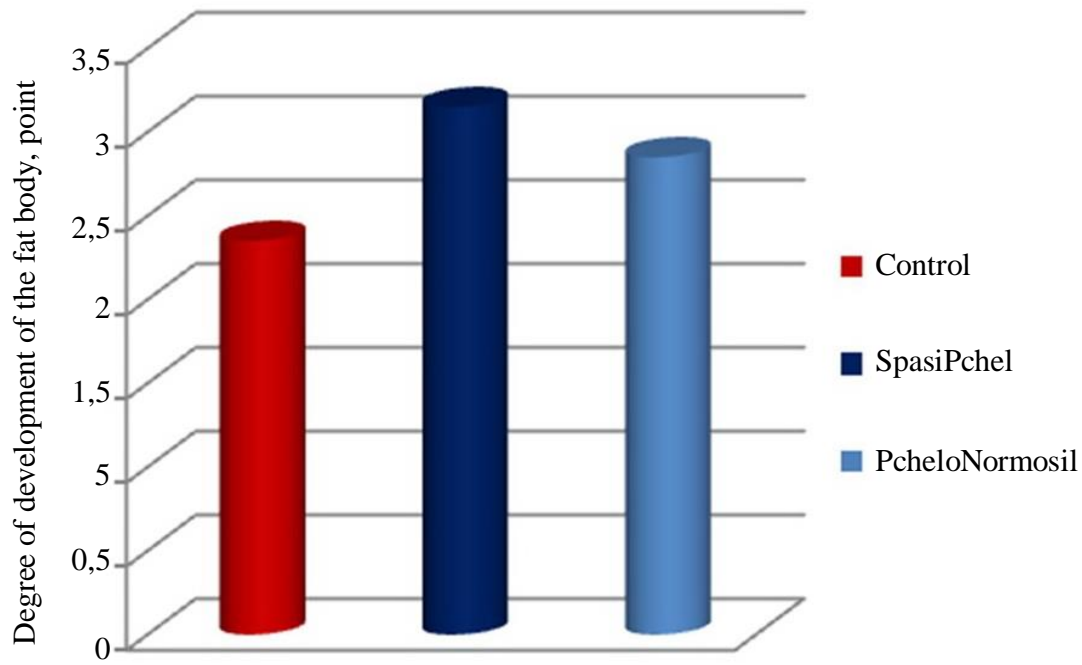

Fig. 2: Degree of development of the fat body of honeybees

A

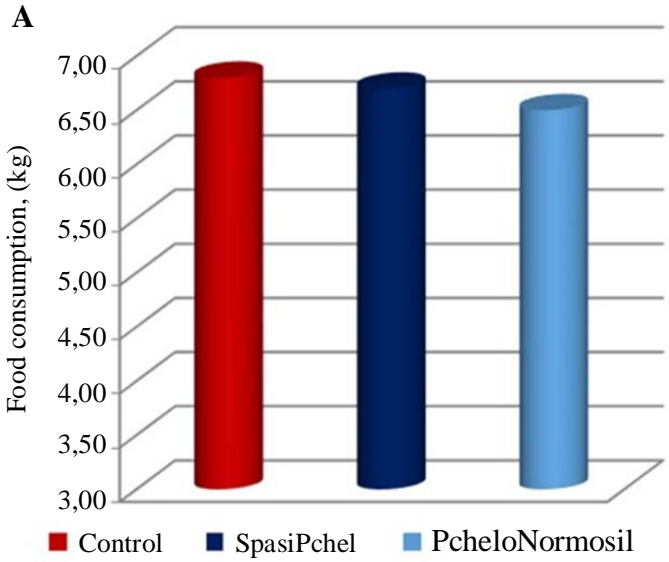

B

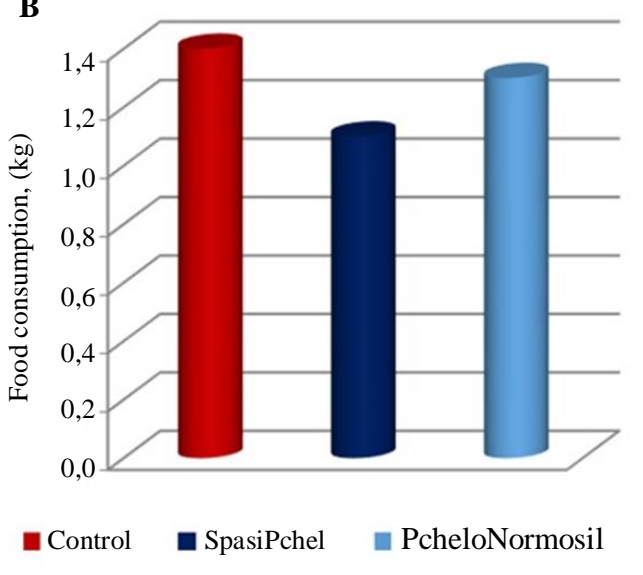

Fig. 3: Food consumption during the wintering period: (A)- per 1 honeybee colony, (B) - per 1 frame, covered with honeybees on both sides 
Table 1: Status of honeybee colonies after overwintering

\begin{tabular}{|c|c|c|c|c|}
\hline \multirow[b]{2}{*}{ Indicator } & \multirow[b]{2}{*}{ Stat. indicator } & \multicolumn{3}{|c|}{ Group of honeybee colonies (type of feeding) } \\
\hline & & $\begin{array}{l}\text { Control group } \\
\text { (Sugar Syrup (SS)) }\end{array}$ & $\begin{array}{l}\text { Experimental group } 1 \\
(\mathrm{SS}+\mathrm{SpasiPchel})\end{array}$ & $\begin{array}{l}\text { Experimental group } 2 \\
(\mathrm{SS}+\text { PcheloNormosil) }\end{array}$ \\
\hline \multirow{3}{*}{$\begin{array}{l}\text { Colony strength, No. of } \\
\text { frame (in autumn) }\end{array}$} & Lim & $4-6$ & $6-8$ & $4-5$ \\
\hline & $\mathrm{M} \pm \mathrm{m}$ & $5.4 \pm 1.2$ & $6.7 \pm 1.2$ & $4.3 \pm 0,6$ \\
\hline & $\begin{array}{l}\% \text { compared to the } \\
\text { control group }\end{array}$ & 100 & 124.1 & 79.6 \\
\hline \multirow{3}{*}{$\begin{array}{l}\text { Colony strength, frame } \\
\text { (in spring) }\end{array}$} & Lim & $4-5$ & $5-6$ & $3-5$ \\
\hline & $\mathrm{M} \pm \mathrm{m}$ & $4.7 \pm 0,6$ & $5.7 \pm 0,6$ & $4.0 \pm 1,0$ \\
\hline & $\begin{array}{l}\% \text { compared to the } \\
\text { control group }\end{array}$ & 100 & 121.3 & 85.1 \\
\hline \multirow{3}{*}{$\begin{array}{l}\text { Amount of sealed brood, } \\
\text { hundreds of cells }\end{array}$} & Lim & $27-97$ & $58-154$ & $53-111$ \\
\hline & $\mathrm{M} \pm \mathrm{m}$ & $61.3 \pm 9.9$ & $97.3 \pm 12.0$ & $75.7 \pm 9.8$ \\
\hline & $\begin{array}{l}\% \text { compared to the } \\
\text { control group }\end{array}$ & 100 & 158.7 & 123.5 \\
\hline
\end{tabular}

Table 2: Mass of dead adult bees and honeybee colonies level of infestation with Nosema spp. spores after taking them out of the wintering building (on average per individual colony), April 2019

\begin{tabular}{llll}
\hline $\begin{array}{l}\text { Group of bee colonies } \\
\text { (type of feeding) }\end{array}$ & Mass of dead adut bees, g & $\begin{array}{l}\text { Number of colonies, affected } \\
\text { by Nosema spp., \% }\end{array}$ & Grade of damage, points \\
\hline $\begin{array}{l}\text { control group (Sugar Syrup (SS)) } \\
\begin{array}{l}\text { Experimental group 1 } \\
\text { (SS + SpasiPchel) }\end{array}\end{array}$ & $73.0 \pm 6.9$ & 8.3 & $1.9 \pm 0.06$ \\
$\begin{array}{l}\text { Experimental group 2 } \\
\text { (SS + PcheloNormosil) }\end{array}$ & $83.0 \pm 7.4$ & 4.2 & $1.7 \pm 0.09$ \\
\hline
\end{tabular}

Food consumption per 1 frame of bees is a more objective indicator. During wintering, the least amount of feed per 1 frame was used by colonies which received SpasiPchel feed additive together with sugar syrup. This was $22.0 \%$ less than the same indicator in control colonies.

The lowest weight of bees died during wintering was revealed in the 2nd group (Table 2). An increased number of dead bees in the 1st experimental group can be explained by the fact that the bee colonies were stronger before wintering.

Both in experimental and control groups there were colonies affected by nosematosis. The maximum number of affected colonies was in experimental group 2 where it reached $12.5 \%$. In other groups this percentage was not very big. There was also a slight increase in the titer of Nosema spp. spores in the intestines of honeybees of experimental group 2 .

\section{Discussion}

The intestinal microflora of honeybees during wintering differs from forages and house bees. This is primarily due to changes in nutrition conditions (D’Alvise et al., 2018; Kešnerová et al., 2020). Feed shortage unbalances intestinal biocenosis, which can lead to a decrease in the resistance of honeybees to temperature stress and diseases (Ludvigsen et al., 2015). In addition, undigested food residues accumulate in honeybees proctodeum during the entire cold period.
This creates favorable conditions for the development of pathogenic microflora. The use of probiotics during autumn feeding of honeybee colonies is aimed at preventing these pathological phenomena.

According to the laboratory studies, feed additives SpasiPchel and PcheloNormosil do not have any toxic effect on bees. On the contrary, there was an increase in lifespan of bees in experimental groups, compared to the control group, which is consistent with the data of (El Khoury et al., 2018).

During tests in field conditions, it was found that the group that received SpasiPchel (B. subtilis) was more prepared for wintering. The strength of colonies in autumn in this group was on average by $24.1 \%$ higher compared to control group of colonies. The degree of development of the fat body of honeybees from this group was also higher by $29 \%$. The effect of bacterial metabolites on fat body development was also reported by (Maggi et al., 2013). Moreover, these data are contradictory, as if the first group of researchers identified a stimulating effect of metabolites on the accumulation of nutrients, the second group didn't not. The authors explain these non-conformances by different concentrations of metabolites solutions used during the experiments (Safonov, 2020).

There is also no consensus on the effect of probiotics on colony strength indicators. During our studies, we found a stimulating effect of a feed additive containing 
bacteria $B$. subtilis on this indicator. At the same time, the complex of Lactobacillus and Bifidobacterium strains did not have a significant effect. This is consistent with the data of (Sabaté et al., 2012; Audisio, 2017), who reported on an increase in the strength of colonies receiving $B$. subtilis. At the same time, according to (Audisio, 2017), both B. subtilis and lactic bacteria had a stimulating effect on the strength of colonies, which can probably be explained by the use of different strains of microorganisms.

Very few studies on the effect of probiotics on honeybee overwintering in continental climate with cold long winters have been conducted. At Apimondia Congress (Bleau et al., 2019) reported on the results of autumn feeding of honeybees with lactic acid bacteria and Saccharomyces cerevisiae. According to their data, there was no effect of probiotics on the honeybee colonies survival during wintering. But there was a small increase of capped brood and Nosema spp. spore reduction. During our studies, we noted that colonies which received $B$. subtilis (SpasiPchel feed additive) in autumn were superior to the control group during spring in both the colony strength and in the amount of sealed brood. Honeybee colonies, that received the complex of Lactobacillus and Bifidobacterium strains (PcheloNormosil feed additive), were a little behind in colony strength compared to the control group, but surpassed them slightly in the amount of sealed brood. As for nosematosis, some increase in the number of affected colonies and the titer of Nosema spp. spores in the second experimental group can be explained by an increase in the $\mathrm{pH}$ in honeybee intestine, which is provoked by lactic bacteria. This creates favorable conditions for parasite development. This is consistent with the data of (Ptaszyńska et al., 2016; Andrearczyk et al., 2014). They also reported on an increase in level of infestation with Nosema spp. spores when honeybee colonies received lactic bacteria.

\section{Conclusion}

Fortification of sugar syrup with SpasiPchel feed additive in autumn contributed to a better preparation of honeybee colonies for wintering. The strength of colonies before they were placed into indoor-wintering building was $24.1 \%$ higher compared to control values. The level of development of the fat body was also higher by 0.8 points. In spring, after honeybees were taken out of wintering building, they exceeded the control group by $21.3 \%$ in colony strength and by $58.7 \%$ in the amount sealed brood. Feed consumption per honeybee frame in these colonies during wintering was $22 \%$ lower compared to the control group.
PcheloNormosil feed additive did not have a significant effect on the strength of colonies and feed consumption, but the amount of sealed brood in these colonies in spring, after honeybees were taken out of wintering building, was $23.5 \%$ higher compared to the control groups.

Thus, the results of our research confirm the possibility of using probiotic feed additives in autumn feeding of bees. However, the efficiency of these feed additives depends on types and strains of microorganisms in their composition. Further research should be made to identify optimal composition of probiotics that are better at preserving honeybee colonies under the conditions of the continental climate characterized by long cold winters.

\section{Funding Information}

This research did not receive any specific grant from funding agencies in the public, commercial, or not-forprofit sectors.

\section{Author's Contributions}

Galina Mishukovskaya: Conceptualisation resources supervision.

Marat Giniyatullin: methodology data curation.

Varis Tuktarov: Software writing - original draft preparation.

Airat Khabirov: Validation writing - review and editing.

Fail Khaziahmetov: Formal analysis visualisation.

Aygul Naurazbaeva: Investigation project administration.

\section{Ethics}

The authors confirm that the present article is original and no ethical issues related to this study.

\section{References}

Andrearczyk, S., Kadhim, M. J., \& Knaga, S. (2014). Influence of a probiotic on the mortality, sugar syrup ingestion and infection of honeybees with Nosema spp. under laboratory assessment. Med Weter, 70, 762-765.

Andreeva, A. V., Nikolaeva, O. N., Ismagilova, E. R., Tuktarov, V. R., Fazlaev, R. G., Ivanov, A. I., ... \& Khakimova, A. Z. (2018). Effect of probiotic preparations on the intestinal microbiome. Journal of Engineering and Applied Sciences, 13(S8), 6467-6472.

Audisio, M. C. (2017). Gram-positive bacteria with probiotic potential for the Apis mellifera L. honey bee: The experience in the northwest of Argentina. Probiotics and antimicrobial proteins, 9(1), 22-31. 
Bleau, N., Derome, N., \& Giovenazzo, P. (2019). The effects of probiotics on winter survival, spring development and gut microbiota of the honey bee (Apis mellifera) in Quebec, Canada. In: 46th APIMONDIA, International Apicultural Congress, Montréal, Canada.

Bonilla-Rosso, G., \& Engel, P. (2018). Functional roles and metabolic niches in the honey bee gut microbiota. Current opinion in microbiology, 43, 69-76.

Chernitskiy, A., Shabunin, S., Kuchmenko, T., \& Safonov, V. (2019). On-farm diagnosis of latent respiratory failure in calves. Turkish Journal of Veterinary and Animal Sciences, 43(6), 707-715.

D’Alvise, P., Böhme, F., Codrea, M. C., Seitz, A., Nahnsen, S., Binzer, M., ... \& Hasselmann, M. (2018). The impact of winter feed type on intestinal microbiota and parasites in honey bees. Apidologie, 49(2), 252-264.

Daisley, B. A., Pitek, A. P., Chmiel, J. A., Al, K. F., Chernyshova, A. M., Faragalla, K. M., ... \& Reid, G. (2020). Novel probiotic approach to counter Paenibacillus larvae infection in honey bees. The ISME Journal, 14(2), 476-491.

Daisley, B. A., Trinder, M., McDowell, T. W., Welle, H., Dube, J. S., Ali, S. N., ... \& Reid, G. (2017). Neonicotinoid-induced pathogen susceptibility is mitigated by Lactobacillus plantarum immune stimulation in a Drosophila melanogaster model. Scientific reports, 7(1), 1-13.

El Khoury, S., Rousseau, A., Lecoeur, A., Cheaib, B., Bouslama, S., Mercier, P. L., ... \& Derome, N. (2018). Deleterious interaction between honeybees (Apis mellifera) and its microsporidian intracellular parasite Nosema ceranae was mitigated by administrating either endogenous or allochthonous gut microbiota strains. Frontiers in Ecology and Evolution, 6, 58.

Fanciotti, M. N., Tejerina, M., Benítez-Ahrendts, M. R., \& Audisio, M. C. (2018). Honey yield of different commercial apiaries treated with Lactobacillus salivarius A3iob, a new bee-probiotic strain. Beneficial microbes, 9(2), 291-298.

Horton, M. A., Oliver, R., \& Newton, I. L. (2015). No apparent correlation between honey bee forager gut microbiota and honey production. PeerJ 3. E1329.

Kešnerová, L., Emery, O., Troilo, M., Liberti, J., Erkosar, B., \& Engel, P. (2020). Gut microbiota structure differs between honeybees in winter and summer. The ISME journal, 14(3), 801-814.

Kešnerová, L., Mars, R. A., Ellegaard, K. M., Troilo, M., Sauer, U., \& Engel, P. (2017). Disentangling metabolic functions of bacteria in the honey bee gut. PLoS biology, 15(12), e2003467.

Khaziakhmetov, F. S., Khabirov, A. F., Avzalov, R. K., Tsapalova, G. R., Rebezov, M. B., Tagirov, K., ... \& Yessimbekov, Z. S. (2018a). Effect of probiotics on calves, weaned pigs and lamb growth. Research Journal of Pharmaceutical, Biological and Chemical Sciences, 9(3), 866-870.
Khaziakhmetov, F., Khabirov, A., Avzalov, R., Tsapalova, G., Rebezov, M., Tagirov, K., ... \& Yessimbekov, Z. (2018b). Valuable effect of using probiotics in poultry farming. Annual Research \& Review in Biology, 1-7.

Ludvigsen, J., Rangberg, A., Avershina, E., Sekelja, M., Kreibich, C., Amdam, G., \& Rudi, K. (2015). Shifts in the midgut/pyloric microbiota composition within a honey bee apiary throughout a season. Microbes and environments, ME15019.

Maes, P. W., Rodrigues, P. A., Oliver, R., Mott, B. M., \& Anderson, K. E. (2016). Diet-related gut bacterial dysbiosis correlates with impaired development, increased mortality and Nosema disease in the honeybee (Apis mellifera). Molecular Ecology, 25(21), 5439-5450.

Maggi, M., Negri, P., Plischuk, S., Szawarski, N., De Piano, F., De Feudis, L., ... \& Audisio, C. (2013). Effects of the organic acids produced by a lactic acid bacterium in Apis mellifera colony development, Nosema ceranae control and fumagillin efficiency. Veterinary Microbiology, 167(3-4), 474-483.

Maurizio, A. (1954). Pollenernährung und Lebensvorgänge bei der Honigbiene (Apis mellifica L.). Landwirtschaftliches Jahrbuch der Schweiz, 68(2), 115-182.

Ptaszyńska, A. A., Borsuk, G., Mułenko, W. I. E. S. Ł. A. W., \& Wilk, J. (2016). Impact of vertebrate probiotics on honeybee yeast microbiota and on the course of nosemosis. Med Weter, 72, 430-434.

Raymann, K., \& Moran, N. A. (2018). The role of the gut microbiome in health and disease of adult honey bee workers. Current opinion in insect science, 26, 97-104.

Sabaté, D. C., Cruz, M. S., Benítez-Ahrendts, M. R., \& Audisio, M. C. (2012). Beneficial effects of Bacillus subtilis subsp. subtilis Mori2, a honey-associated strain, on honeybee colony performance. Probiotics and antimicrobial proteins, 4(1), 39-46.

Safonov, V. (2020). Assessment of Heavy Metals in Milk Produced by Black-and-White Holstein Cows from Moscow. Current Research in Nutrition and Food Science Journal, 8(2), 410-415.

Stephan, J. G., Lamei, S., Pettis, J. S., Riesbeck, K., de Miranda, J. R., \& Forsgren, E. (2019). Honeybee-specific lactic acid bacterium supplements have no effect on American foulbrood-infected honeybee colonies. Applied and environmental microbiology, 85(13).

Yoshiyama, M., Wu, M., Sugimura, Y., Takaya, N., Kimoto-Nira, H., \& Suzuki, C. (2013). Inhibition of Paenibacillus larvae by lactic acid bacteria isolated from fermented materials. Journal of Invertebrate Pathology, 112(1), 62-67. 